\title{
It's all about control: Sense of control mediates the relationship between physical activity and mental health during the COVID-19 pandemic in Germany
}

\author{
Lena-Marie Precht $^{1} \mathbb{D} \cdot$ Jürgen Margraf ${ }^{1} \mathbb{D} \cdot$ Jan Stirnberg $^{1} \mathbb{D} \cdot$ Julia Brailovskaia $^{1} \mathbb{D}$
}

Accepted: 9 September 2021

(c) The Author(s) 2021

\begin{abstract}
COVID-19-related burden has a significant impact on mental health and has led to an increase of depression, anxiety, and stress symptoms. Physical activity has been suggested to mitigate the negative effects of the pandemic and to foster mental health. The present study aimed to investigate, whether sense of control might mediate the supposed beneficial effects of physical activity on positive (PMH) and negative mental health $(\mathrm{NMH})$ in unpredictable extraordinary situations. Data were assessed in a sample of 568 students $\left(M_{\mathrm{age}}=19.90, S D_{\mathrm{age}}=4.52\right)$ from Germany via an online survey in fall 2020. Mediation analyses revealed that sense of control mediated the relation between physical activity and PMH as well as depression, anxiety, and stress symptoms, respectively. The findings indicate that physical activity may be a promising strategy for fostering sense of control and thus mental health. Due to its practical implications and practicability, engagement in physical activity could be an effective way to reduce the NMH consequences of the current COVID-19 situation, and therefore should be addressed in actions for long-term prevention and intervention.
\end{abstract}

Keywords COVID-19 $\cdot$ Physical activity $\cdot$ Sense of control $\cdot$ Positive mental health $\cdot$ Depression, anxiety, stress

\section{Introduction}

On March 11, 2020, the World Health Organization (WHO) declared the outbreak of the coronavirus disease (COVID19 ; caused by the severe acute respiratory syndrome coronavirus 2, SARS-CoV-2) as a pandemic (World Health Organization, 2020a). The following governmental induced restrictive measures for the prevention of its rapid spread - including physical distancing measures, movement restrictions, and wearing of face masks (Tso \& Cowling, 2020;

Lena-Marie Precht

lena-marie.precht@rub.de

Jürgen Margraf

juergen.margraf@rub.de

Jan Stirnberg

jan.stirnberg@rub.de

Julia Brailovskaia

julia.brailovskaia@rub.de

1 Mental Health Research and Treatment Center, Department of Clinical Psychology and Psychotherapy, Ruhr-Universität Bochum, Massenbergstr. 9-13, 44787 Bochum, Germany
World Health Organization, 2020b) - have significantly changed people's everyday life. While some individuals adapted to the situation and tried to make the best of it, others experienced it as a heavy burden (Brailovskaia \& Margraf, 2020). As a consequence, mental health declined (Fruehwirth et al., 2021; Pierce et al., 2020). A recent metaanalysis, based on samples from all over the word, revealed a prevalence of $33.7 \%, 31.9 \%$, and $29.6 \%$ for depression, anxiety, and stress, respectively (Salari et al., 2020).

Anxiety resulting from the pandemic outbreak (Liu et al., 2020), loneliness due to social distancing and isolation (Galea et al., 2020), uncertainties regarding the future (Paredes et al., 2021), and feelings of lack of control (Šrol et al., 2021) have a significant impact on mental health. Traditionally, mental health has been defined as the mere absence of mental illness. However, in recent years it has been recognized that the absence of mental disorders is not the same as the presence of mental health (Keyes, 2005; Lukat et al., 2016). Therefore, mental health is often considered as two interrelated but separate unipolar dimensions, which can be present simultaneously (Keyes, 2005): positive mental health (PMH) and negative mental health (NMH). While PMH comprises facets of subjective and 
psychological aspects of well-being, NMH refers to mental health problems, psychopathology, or negative well-being (Lukat et al., 2016). In order to reduce the risk of developing mental health problems and to support mental and psychosocial well-being, general advice was provided to the population, e.g., staying in contact with family and friends, limiting the amount of COVID-19 information sources, and maintaining daily routine (Fiorillo \& Gorwood, 2020; World Health Organization, 2020c). In addition, maintaining regular physical activity such as jogging, cycling, or swimming has been proposed as an important strategy for mitigating the negative effects of the pandemic on physical and mental health (Brailovskaia et al., 2021; Chen et al., 2020).

Considering physical health, recent research suggests that physical activity can enhance immune defense and reduce the harmful effects of stress on immunity, may be protective for lung function, has the potential to reduce the severity of COVID-19 infections, and improves the immune response to vaccination (Sallis \& Pratt, 2020; Simpson \& Katsanis, 2020; Woods et al., 2020). Regarding mental health, physical activity is generally known for enhancing self-esteem and resilience to stressful experiences as well as reducing depression and anxiety (Eime et al., 2013; Rebar et al., 2015). In terms of the pandemic, recent studies demonstrated that physical activity could foster mood and well-being (Brand et al., 2020; Maugeri et al., 2020) and is negatively related to perceived burden caused by COVID-19 (Brailovskaia et al., 2021). In addition, some evidence indicates, that physical activity might boost self-efficacy, feelings of mastery, and sense of control which in turn could contribute to an increase of PMH and a decrease of NMH (Bailey et al., 2013; Mikkelsen et al., 2017).

Sense of control is an important personal (coping) resource, that describes the belief that the events and conditions in one's life are controllable by own actions rather than being a consequence of luck, chance, or fortune (Glavin \& Schieman, 2014; Pearlin \& Schooler, 1978). Persons with a high sense of control effectively cope with stressors by trying alternative actions if their current behavior does not contribute to a functional solution of the stressful situation (Ross \& Mirowsky, 2013). Accordingly, this resource is associated with less distress and a lower risk for mental disorders, e.g., substance use disorder (Kiecolt et al., 2009). Various studies demonstrated relations between sense of control and PMH outcomes (for review see e.g., Ross \& Mirowsky, 2013). Especially in extraordinary situations, which are characterized by lots of uncertainties (Šrol et al., 2021), sense of control can be of significant importance. Presumably, some people rely on maladaptive strategies to compensate the reduced sense of control, e.g., by adopting conspiracy beliefs (Šrol et al., 2021), engaging in intensive social media usage (Brailovskaia \& Margraf, 2021), and problematic internet usage in general (Islam et al., 2020;
Lemenager et al., 2020). Moreover, a recent study found a positive effect of sense of control on emotional well-being (Yang \& Ma, 2020), suggesting that (regaining) sense of control might reduce stress, anxiety, and depressed mood.

Considering the presented background, it is important to identify and foster factors that boost sense of control and thereby can alleviate the detrimental effects of the pandemic outbreak on mental health (Yang \& Ma, 2020). While it was already shown that PMH (Brailovskaia \& Margraf, 2020), higher trust in institution's response to the pandemic (Šrol et al., 2021) and perceived knowledge (Yang \& Ma, 2020) are positively related to sense of control, the main aim of the present study was to investigate the relationship between physical activity and sense of control, which is supposed to be associated with mental health. For a complete mental health assessment according to the dual-factor model (e.g., Keyes, 2005), PMH (Lukat et al., 2016) as well as NMH, operationalized as depression, anxiety, and stress symptoms (Lovibond \& Lovibond, 1995), were considered altogether.

Based on this framework, following hypotheses are presumed. As research considering physical activity during COVID-19 described positive relations with mental health (e.g., Faulkner et al., 2021), physical activity was assumed to be positively related to PMH (Hypothesis 1a) and negatively related to symptoms of depression (Hypothesis $1 \mathrm{~b}$ ), anxiety (Hypothesis 1c), and stress (Hypothesis 1d). Furthermore, there is the assumption, that physical activity might foster the individual sense of control, e.g., by the improvement of one's performance or the achievement of self-imposed physical goals (Bailey et al., 2013). Therefore, it was expected that there is a positive link between physical activity and sense of control (Hypothesis 2). Moreover, sense of control was presumed to be positively related to PMH (Hypothesis 3a) and negatively related to symptoms of depression (Hypothesis 3b), anxiety (Hypothesis 3c), and stress (Hypothesis 3d). Finally, the relations between physical activity and PMH as well as symptoms of depression, anxiety, and stress were hypothesized to be mediated by sense of control (Hypotheses $4 a-4 d)$.

\section{Methods}

\section{Procedure and Participants}

The sample consisted of 568 participants ( $69 \%$ women; $M_{\text {age }}$ $\left(S D_{a g e}\right)=19.90$ (4.52), range: 16-66) who were currently enrolled at a large university in the Ruhr region in Germany. Data were collected between October and November 2020, when measures for preventing the spread of COVID-19 - including physical distancing measures, limitation of people gathering, shutdown of specific institutions, and wearing of face masks - were still present (Bundesministerium für 
Gesundheit, 2021). The online survey took place within the frame of the ongoing Bochum Optimism and Mental Health (BOOM) program, that investigates risk and protective factors of mental health (Maercker et al., 2015; Schönfeld et al., 2017). All participants have been invited to participate by e-mail. They were properly instructed and gave informed consent via an online form. Participation was voluntary and compensated by course credits. The study has received ethical approval from the responsible Ethics Committee. There were no missing data. Power analyses using the $\mathrm{G}^{*}$ Power program, version 3.1 (Faul et al., 2009) indicated that the sample size was sufficient for valid results (power $>.80, \alpha$ $=.05$, effect size: $f^{2}=.02$; cf., Cohen, 1992).

\section{Materials}

Physical activity The frequency of physical activity was assessed by the item "How frequently did you engage in physical activity (e.g., jogging, cycling) in the last 12 months?". It was rated on a 5-point Likert-type scale $(1=$ never, 5 = four times a week or more) and was shown to be a reliable and valid instrument to measure physical activity (Brailovskaia et al., 2021; Milton et al., 2011).

Sense of control According to Brailovskaia and Margraf (2021) sense of control was measured with the two items "Do you experience important areas of your life (i.e., work, free-time, family, etc.) to be uncontrollable, meaning that you cannot or barely can influence them?" and "Do you experience these important areas of your life as unpredictable or inscrutable?". They were rated on a 5-point Likerttype scale ranging from 0 (not at all) to 4 (very strong), so that higher sum scores indicate lower sense of control. Current scale reliability was $\alpha=.76$.

Positive mental health The unidimensional Positive Mental Health Scale (PMH-scale; Lukat et al., 2016) served for the assessment of PMH. The nine items (e.g., "I enjoy my life") were rated on a 4-point Likert-type scale $(0=$ do not agree, 3 = agree), with higher sum scores indicating higher levels of PMH. Current scale reliability was $\alpha=.91$.

Negative mental health $\mathrm{NMH}$ was measured by the Depression Anxiety Stress Scales 21 (DASS-21; Lovibond \& Lovibond, 1995). The questionnaire contains seven items for each subscale: depression (e.g., "I couldn't seem to experience any positive feeling at all"), anxiety (e.g., "I felt scared without any good reason"), and stress symptoms (e.g., "I tended to over-react to situations"). The items were rated on a 4-point Likert-type scale $(0=$ did not apply to me at all, 3 = applies to me very much or most of the time). Higher sum scores indicate higher symptoms of depression, anxiety, and stress, respectively. Current scale reliabilities were $\alpha=.92$ for depression, $\alpha=.83$ for anxiety, and $\alpha=.87$ for stress.

\section{Statistical Analyses}

Statistical analyses were conducted using SPSS 27 and the macro PROCESS version 3.5.3 (Hayes, 2020). After descriptive statistics, the relationship between physical activity, sense of control, $\mathrm{PMH}$, and the $\mathrm{NMH}$ constructs (i.e., symptoms of depression, anxiety, and stress) was assessed by zero-order bivariate correlations. Next, four mediation models (PROCESS: model 4) were calculated. Each model included physical activity as predictor and sense of control as mediator. PMH (model 1), depression (model 2), anxiety (model 3), and stress (model 4), respectively, served as outcome. Age and gender, which were considered as control variables, were included as covariates. In all mediation models, the basic relationship between predictor and outcome was referred to as $c$ (total effect), the path of predictor to mediator as $a$ and the path of mediator to outcome was referred to as $b$. The combined effect of paths $a$ and $b$ represented the indirect effect $(a b)$, and the direct effect of predictor to outcome after the inclusion of the mediator in the model was referred to as $c$ '. The mediation effect was assessed by bootstrapping procedure $(10,000$ samples), which provides percentile bootstrap confidence intervals $(95 \% \mathrm{CI})$.

\section{Results}

Table 1 displays the descriptive statistics of the investigated variables and their correlations. The means of the NMH constructs depression, anxiety, and stress were 7.24 (disorder cut-off $\geq 10$ ), 5.58 (disorder cut-off $\geq 6$ ), and 8.62 (disorder cut-off $\geq 10$ ), respectively. All investigated constructs were significantly correlated $(p<.001)$ (see Table 1$)$. Physical activity was positively related to $\mathrm{PMH}$ and negatively related to sense of control (whereupon higher values indicate a lower sense of control) as well as to symptoms of depression, anxiety, and stress. Sense of control was negatively related to $\mathrm{PMH}$ and positively related to symptoms of depression, anxiety, and stress. PMH was negatively related to all NMH constructs. The NMH constructs were positively correlated.

Figure 1 shows the results of the bootstrapped mediation analyses with physical activity as predictor, sense of control as mediator and (a) PMH as well as (b) NMH, namely stress symptoms, as outcomes. The results of all four mediation models that are presented in Table 2 indicate that sense of control mediates the relationship between physical activity and $\mathrm{PMH}$ as well as depression, anxiety, and stress symptoms, respectively. The basic relationships between physical 
Table 1 Descriptive statistics and correlations of physical activity, sense of control, positive mental health (PMH), depression, anxiety, and stress symptoms.
Fig. 1 (a) Mediation model including physical activity (predictor), sense of control (mediator) and positive mental health (outcome); (b) Mediation model including physical activity (predictor), sense of control (mediator) and stress (outcome). Note. $c=$ total effect, $c^{\prime}=$ direct effect; $b$ : standardized regression coefficient, $S E$ : standard error, CI: confidence interval.

\begin{tabular}{llllllll}
\hline & $M(S D)$ & Min-Max & $(2)$ & $(3)$ & $(4)$ & $(5)$ & (6) \\
\hline (1) Physical activity & $3.32(1.22)$ & $1-5$ & $-.177^{* *}$ & $.276^{* *}$ & $-.237^{* *}$ & $-.193^{* *}$ & $-.145^{* *}$ \\
(2) Sense of control & $3.26(1.95)$ & $0-8$ & & $-.524^{* *}$ & $.522^{* *}$ & $.455^{* *}$ & $.482^{* *}$ \\
(3) PMH & $16.60(5.82)$ & $1-27$ & & & $-.762^{* *}$ & $-.543^{* *}$ & $-.621^{* *}$ \\
(4) Depression & $7.24(5.82)$ & $0-21$ & & & & $.610^{* *}$ & $.649^{* *}$ \\
(5) Anxiety & $5.58(4.80)$ & $0-20$ & & & & & $.748^{* *}$ \\
(6) Stress & $8.62(5.11)$ & $0-21$ & & & & & \\
\hline
\end{tabular}

Note. $N=568 ; M=$ mean, $S D=$ standard deviation, $M i n=$ minimum, $M a x=$ maximum; Sense of control: the higher the value, the lower sense of control; $* * p<.001$.
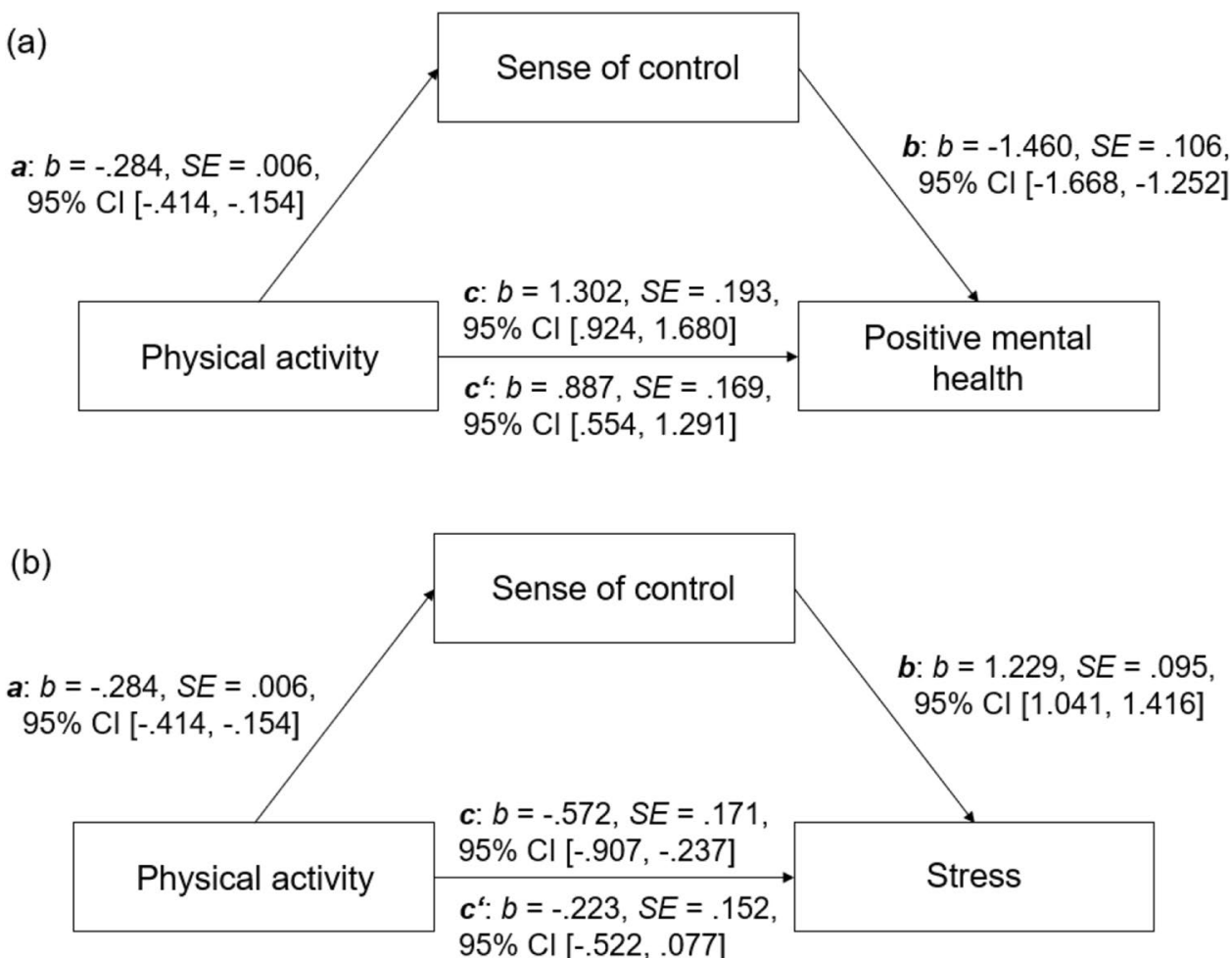

\begin{tabular}{|c|c|c|c|c|c|c|c|c|c|}
\hline \multirow[t]{2}{*}{ Outcome } & \multicolumn{3}{|c|}{ Total effect } & \multicolumn{3}{|c|}{ Direct effect } & \multicolumn{3}{|c|}{ Indirect effect } \\
\hline & $c$ & $S E$ & $95 \%$ CI & $c^{\prime}$ & $S E$ & $95 \% \mathrm{CI}$ & $a b$ & $S E$ & $95 \% \mathrm{CI}$ \\
\hline PMH & 1.302 & .193 & $\begin{array}{l}{[.924,} \\
1.680]\end{array}$ & .887 & .169 & $\begin{array}{l}{[.554,} \\
1.219]\end{array}$ & .415 & .108 & $\begin{array}{l}{[.207,} \\
.628]\end{array}$ \\
\hline Depression & -1.139 & .194 & $\begin{array}{l}{[-1.521,} \\
-.758]\end{array}$ & -.722 & .171 & $\begin{array}{l}{[-1.057,} \\
-.386]\end{array}$ & -.418 & .108 & $\begin{array}{l}{[-.632,} \\
-.210]\end{array}$ \\
\hline Anxiety & -.739 & .159 & $\begin{array}{l}{[-1.050,} \\
-.427]\end{array}$ & -.438 & .145 & $\begin{array}{l}{[-.722,} \\
-.154]\end{array}$ & -.301 & .078 & $\begin{array}{l}{[-.457,} \\
-.154]\end{array}$ \\
\hline Stress & -.572 & .171 & $\begin{array}{l}{[-.907,} \\
-.237]\end{array}$ & -.223 & .152 & $\begin{array}{l}{[-.522,} \\
.077]\end{array}$ & -.349 & .090 & $\begin{array}{l}{[-.527,} \\
-.173]\end{array}$ \\
\hline
\end{tabular}

Note. $N=568 ; S E=$ standard error; $\mathrm{CI}=$ confidence interval; all CIs generated with bootstrapping: $\mathrm{N}=$ 10,$000 ; c=$ total effect, $c^{\prime}=$ direct effect, $a b=$ indirect effect.
Table 2 Estimated coefficients of the mediation models with physical activity as predictor, sense of control as mediator as well as positive mental health (PMH), depression, anxiety, and stress as outcomes (controlling for age and gender). and sense of control (path $a: p<.001$ ) and the associations between physical activity and all four outcomes (path $b$ : $p<$ 
.001) were also significant. While the relationship between physical activity and stress was no longer significant after the inclusion of sense of control in the model (direct effect $\left.c^{\prime}: p=.144\right)$, the relationships between physical activity and $\mathrm{PMH}$, depression, and anxiety, respectively, remained significant $\left(c^{\prime}: p<.01\right)$. However, the total effects were higher than the direct effects (see Table 2). All indirect effects $(a b)$ were significant (see Table 2).

\section{Discussion}

Since the beginning of 2020, COVID-19 has spread all over the globe. Although global case and death incidences are recently decreasing (World Health Organization, 2021b) and the access to effective vaccines (World Health Organization, 2021a) seems promising to combat the virus, the end of the pandemic is not yet foreseeable. It still affects daily life and has a large mental health impact not only on vulnerable groups, including healthcare professionals, people with pre-existing mental health issues and those infected with COVID-19, but also on the general population (Tsamakis et al., 2021). In addition, experts forecast that this impact can persist and be long lasting for several years during the post-pandemic time and expect increases in the prevalence of mental disorders and suicide (Kathirvel, 2020). Therefore, it is important to not only strengthen and expand mental health services, namely in terms of full- and semi-inpatient as well as outpatient care, but also to identify and communicate low-threshold prevention and intervention strategies - e.g., the reduction of social media usage or reaching adequate amounts of physical activity (see e.g., Brailovskaia et al., 2020) - that may foster mental health in the general population.

Regular physical activity has been suggested as an important approach for mitigating the negative effects of the pandemic on physical and mental health (Chen et al., 2020; Sallis \& Pratt, 2020). Since evidence suggests that physical activity is positively linked to mental health in general (e.g., Mikkelsen et al., 2017) and especially during the pandemic (e.g., Brailovskaia et al., 2021; Brand et al., 2020), and there is also evidence for the importance of sense of control (e.g., Yang \& Ma, 2020), the present study investigated the relationship between physical activity and PMH as well as $\mathrm{NMH}$, while considering the role of sense of control. The current results revealed that sense of control mediates the relation between physical activity and PMH as well as depression, anxiety, and stress symptoms, respectively.

As expected, physical activity was positively related to PMH and negatively related to depression, anxiety, and stress (small effect sizes; confirmation of Hypotheses 1a $-1 d)$. This is in line with numerous previously published studies (for review see e.g., Eime et al., 2013; Rebar et al.,
2015). But also recently conducted studies reported relations with PMH and NMH with reference to the COVID-19 situation. Across different countries, physical activity was positively related to different forms of well-being and quality of life (Faulkner et al., 2021; Lesser \& Nienhuis, 2020; Ozdemir et al., 2020) as well as negatively linked to depression, anxiety, and stress (Jacob et al., 2020; Li et al., 2021; Xiang et al., 2020). Furthermore, it has been shown that physical activity can contribute to less psychological burden and a more adaptive response to the current COVID-19 situation (Brailovskaia et al., 2021).

There are several possible explanations for the beneficial effects of physical activity (Mikkelsen et al., 2017). However, the present study investigated whether physical activity might foster sense of control - a construct directly linked to stress responses and well-being (Steptoe \& Poole, 2016) - and thus mental health. As expected, sense of control (higher values indicate lower sense of control) was negatively related to physical activity (small effect; confirmation of Hypothesis 2) and PMH (large effect; confirmation of Hypothesis 3a). Moreover, it was positively related to symptoms of depression (large effect; confirmation of Hypothesis $3 b$ ), anxiety, and stress (medium effect sizes; confirmation of Hypotheses 3c and 3d). The confirmation of Hypothesis 2 supports previous studies suggesting that physical activity might foster sense of control (Bailey et al., 2013; Brailovskaia \& Margraf, 2021). This could be explained by a possible increase of social networks and community cohesion in team sport or - in times of physical distancing more likely - by experiencing the steady improvement of one's sportive performance or the achievement of self-imposed physical goals.

The present findings regarding the relations between sense of control and PMH as well as depression, anxiety, and stress complement previous results that emphasized a positive effect of sense of control on emotional well-being (Yang \& Ma, 2020) and levels of distress (Ross \& Mirowsky, 2013). In addition, individuals with low sense of control are at risk for NMH outcomes like depression, anxiety, and burnout (Maier \& Seligman, 2016; Southwick \& Southwick, 2018) and tend to engage in maladaptive coping strategies such as overeating, problematic drinking, smoking, or use of psychoactive substances which in turn might lead to acute stress (Ye et al., 2020).

Results of the mediation analyses indicated that sense of control mediates the relation between physical activity and $\mathrm{PMH}$, as well as symptoms of depression, anxiety, and stress (confirmation of Hypotheses $4 \mathrm{a}-4 \mathrm{~d}$ ). Hence, it can be assumed, that physical activity might foster or even help to regain sense of control, which can enhance $\mathrm{PMH}$ and reduce NMH. This is of specific important in the current COVID-19 situation that is often experienced as a heavy psychological burden (Brailovskaia \& Margraf, 2020). The 
finding, that the direct effects between physical activity and $\mathrm{PMH}$, and symptoms of depression and anxiety, respectively, remained significant after adding sense of control to the model points out to the numerous other mechanisms that can influence the relationship between physical activity and mental health (for review see e.g., Mikkelsen et al., 2017). The no longer significant direct effect in the relation between physical activity and stress symptoms might be explained as following. It seems that stress symptoms could function as another mediator in the relation between physical activity and depression as well as anxiety. In accordance with this, a recent study revealed that stress symptoms may lead to symptoms of depression or anxiety which could later lead to depression (Rodríguez-Hidalgo et al., 2020). This means, that individuals engaging in physical activity could profit from an enhanced sense of control that helps to reduce the experience of stress and thereby, in the long term, the risk for anxiety and depression.

The potential of physical activity to foster sense of control and thereby mental health is of practical importance in two respects. On the one hand, the pandemic outbreak and its consequences have led to an increase of symptoms of depression, anxiety, and stress (Fruehwirth et al., 2021; Pierce et al., 2020). Since aftermath are expected to be long lasting (Kathirvel, 2020), physical activity can be seen as a cost-effective, low-threshold prevention or intervention strategy. As the current study only considered the frequency of physical activity, the present results do not allow inferences concerning advice for the type and further characteristics of physical activity. However, the WHO recommends at least 150 minutes of moderate- or 75 minutes of vigorous-intensity physical activity as well as two sessions of strength training per week (World Health Organization, 2010). Furthermore, recent studies reported running, walking, and cycling (Lesser \& Nienhuis, 2020), as well as stretching and resistance training (Xiang et al., 2020) to be beneficial for mental health in times of the pandemic, which is meaningful, since these activities require no specific equipment, only little space and can be practiced at any time at home or outdoors (Chen et al., 2020). Moreover, they can be carried out alone, which seems promising, since team sports that were previously shown to be beneficial for mental health (Chekroud et al., 2018; Johnston et al., 2020) have been banned as well as any other community activities in many countries since the COVID-19 outbreak. On the other hand, sense of control has been proven to be positively related to mental health during the pandemic (Brailovskaia \& Margraf, 2020; Yang $\&$ Ma, 2020). Furthermore, it can also lead to a reduction of maladaptive coping strategies, like intensive social media usage, as a response to negative feelings (Brailovskaia \& Margraf, 2021). Consequently, experiencing a high sense of control is not only beneficial in extraordinary situations such as the outbreak of COVID-19, but also when being confronted with stressors of daily life, e.g., problems with family or friends, or at the workplace. Especially for students who are often exposed to a high pressure to perform, a high level of sense of control can be an important resource for functional coping with the stressful experiences. Thus, the investigation and communication of strategies fostering sense of control are of special importance.

Despite the novelty and the practical importance of the present results, some limitations must be considered. First, the cross-sectional online survey design allows only hypothetical conclusions of causality. Due to social distancing measures in Germany by the time of data collection, experimental investigations were not possible. However, a replication of the present findings in longitudinal experimental studies that address physical activity is eligible. Second, it must be noted that present results are a snapshot of the COVID-19 situation in Germany in fall 2020. Due to the dynamic circumstances of the pandemic as well as different courses and measures for the prevention of the spread of the virus in other countries, it should be investigated whether the relations are replicable in other samples to different timepoints. Third, the convenient sample of young university students that are mostly female limits the generalizability of the results. Although age and gender were controlled for in the analyses, future studies should replicate the findings in more age and gender balanced samples. Further, in favor of more representative samples, the consideration of non-WEIRD (western, educated, industrialized, rich, and democratic; Henrich et al., 2010) populations seems worthwhile. Fifth, it is also necessary to investigate at-risk groups like people with pre-existing mental health issues or those who recovered from a COVID-19 infection to find out whether physical activity proves to be an effective intervention strategy under these pre-conditions. Lastly, there were only small effect sizes of the relations between physical activity and sense of control as well as PMH and NMH. Future studies could use well-established, reliable instruments like the International Physical Activity Questionnaire (IPAQ; Craig et al., 2003) for a differentiated assessment of physical activity and investigate further potential moderators (e.g., duration, intensity, or type) of the relationship between the constructs.

In conclusion, the present study provides the first findings from Germany that physical activity might be a promising strategy for fostering sense of control and thereby mental health. This underlines the importance of getting or staying active not only throughout extraordinary situations like the one caused by the COVID-19 outbreak, but also under common circumstances. Since physical activity can be seen as a cost-effective strategy for improving mental health, governmental and healthcare professionals' actions are required to foster its implementation - not only to prevent the negative 
consequences of the current situation but also to protect people's mental health in the long term.

\begin{abstract}
Author's contributions Lena-Marie Precht, Jürgen Margraf, Jan Stirnberg and Julia Brailovskaia conducted the study design. Lena-Marie Precht conducted literature searches and statistical analysis and wrote the first draft of the manuscript. Jürgen Margraf and Julia Brailovskaia conducted data collection. Lena-Marie Precht and Julia Brailovskaia conducted data preparation. Jürgen Margraf, Jan Stirnberg and Julia Brailovskaia reviewed and edited the first draft. All authors state their compliance with the Code of Ethics of the World Medical Association (Declaration of Helsinki).
\end{abstract}

Funding Open Access funding enabled and organized by Projekt DEAL. The Volkswagen Foundation provided financial support for the conduct of the research. The funding source had no role in study design, the collection, analysis and interpretation of data, in the writing of the report, and in the decision to submit the article for publication.

Data availability The dataset generated and analyzed during the current study is available from the corresponding author upon reasonable request.

Code availability Not applicable.

\section{Declarations}

Ethics approval This study was performed in line with the principles of the Declaration of Helsinki and has received ethical approval from the responsible Ethics Committee.

Consent to participate Informed consent was obtained from all individual participants included in the study.

Consent for publication All individual participants have consented to the inclusion of their data in this study.

Conflicts of interest The authors have no conflicts of interest to declare that are relevant to the content of this article.

Open Access This article is licensed under a Creative Commons Attribution 4.0 International License, which permits use, sharing, adaptation, distribution and reproduction in any medium or format, as long as you give appropriate credit to the original author(s) and the source, provide a link to the Creative Commons licence, and indicate if changes were made. The images or other third party material in this article are included in the article's Creative Commons licence, unless indicated otherwise in a credit line to the material. If material is not included in the article's Creative Commons licence and your intended use is not permitted by statutory regulation or exceeds the permitted use, you will need to obtain permission directly from the copyright holder. To view a copy of this licence, visit http://creativecommons.org/licenses/by/4.0/.

\section{References}

Bailey, R., Hillman, C., Arent, S., \& Petitpas, A. (2013). Physical activity: An underestimated investment in human capital? Journal of Physical Activity \& Health, 10(3), 289-308. https://doi.org/10. 1123/jpah.10.3.289

Brailovskaia, J., Cosci, F., Mansueto, G., Miragall, M., Herrero, R., Baños, R. M., Krasavtseva, Y., Kochetkov, Y., \& Margraf,
J. (2021). The association between depression symptoms, psychological burden caused by Covid-19 and physical activity: An investigation in Germany, Italy, Russia, and Spain. Psychiatry Research, 295, 113596. https://doi.org/10.1016/j.psychres.2020. 113596

Brailovskaia, J., \& Margraf, J. (2020). Predicting adaptive and maladaptive responses to the coronavirus (Covid-19) outbreak: A prospective longitudinal study. International Journal of Clinical and Health Psychology, 20(3), 183-191. https://doi.org/10.1016/j. ijchp.2020.06.002

Brailovskaia, J., \& Margraf, J. (2021). The relationship between burden caused by coronavirus (Covid-19), addictive social media use, sense of control and anxiety. Computers in Human Behavior, 119, 106720. https://doi.org/10.1016/j.chb.2021.106720

Brailovskaia, J., Ströse, F., Schillack, H., \& Margraf, J. (2020). Less Facebook use - More well-being and a healthier lifestyle? An experimental intervention study. Computers in Human Behavior, 108, 106332. https://doi.org/10.1016/j.chb.2020.106332

Brand, R., Timme, S., \& Nosrat, S. (2020). When pandemic hits: Exercise frequency and subjective well-being during Covid-19 pandemic. Frontiers in Psychology, 11, 570567. https://doi.org/ 10.3389/fpsyg.2020.570567

Bundesministerium für Gesundheit. (2021). Coronavirus-Pandemie (SARS-CoV-2): Chronik bisheriger Maßnahmen und Ereignisse. Retrieved from https://www.bundesgesundheitsministerium.de/ coronavirus/chronik-coronavirus.html (last access July 06, 2021).

Chekroud, S. R., Gueorguieva, R., Zheutlin, A. B., Paulus, M., Krumholz, H. M., Krystal, J. H., \& Chekroud, A. M. (2018). Association between physical exercise and mental health in 1.2 million individuals in the USA between 2011 and 2015: A cross-sectional study. The Lancet Psychiatry, 5(9), 739-746. https://doi.org/10. 1016/S2215-0366(18)30227-X

Chen, P., Mao, L., Nassis, G. P., Harmer, P., Ainsworth, B. E., \& Li, F. (2020). Coronavirus disease (Covid-19): The need to maintain regular physical activity while taking precautions. Journal of Sport and Health Science, 9(2), 103-104. https://doi.org/10. 1016/j.jshs.2020.02.001

Cohen, J. (1992). A power primer. Psychological Bulletin, 112(1), 155-159. https://doi.org/10.1037/0033-2909.112.1.155

Craig, C. L., Marshall, A. L., Sjöström, M., Bauman, A. E., Booth, M. L., Ainsworth, B. E., Pratt, M., Ekelund, U., Yngve, A., Sallis, J. F., \& Oja, P. (2003). International physical activity questionnaire: 12-country reliability and validity. Medicine \& Science in Sports \& Exercise, 35(8), 1381-1395. https://doi.org/10.1249/01.mss. 0000078924.61453.fb

Eime, R. M., Young, J. A., Harvey, J. T., Charity, M. J., \& Payne, W. R. (2013). A systematic review of the psychological and social benefits of participation in sport for adults: Informing development of a conceptual model of health through sport. The International Journal of Behavioral Nutrition and Physical Activity, 10, 135. https://doi.org/10.1186/1479-5868-10-135

Faul, F., Erdfelder, E., Buchner, A., \& Lang, A.-G. (2009). Statistical power analyses using $G^{*}$ power 3.1: Tests for correlation and regression analyses. Behavior Research Methods, 41(4), 11491160. https://doi.org/10.3758/BRM.41.4.1149

Faulkner, J., O’Brien, W. J., McGrane, B., Wadsworth, D., Batten, J., Askew, C. D., Badenhorst, C., Byrd, E., Coulter, M., Draper, N., Elliot, C., Fryer, S., Hamlin, M. J., Jakeman, J., Mackintosh, K. A., McNarry, M. A., Mitchelmore, A., Murphy, J., Ryan-Stewart, H., \& Lambrick, D. (2021). Physical activity, mental health and well-being of adults during initial Covid-19 containment strategies: A multi-country cross-sectional analysis. Journal of Science and Medicine in Sport, 24(4), 320-326. https://doi.org/10.1016/j. jsams.2020.11.016

Fiorillo, A., \& Gorwood, P. (2020). The consequences of the Covid-19 pandemic on mental health and implications for clinical practice. 
European Psychiatry, 63(1), e32. https://doi.org/10.1192/j.eurpsy. 2020.35

Fruehwirth, J. C., Biswas, S., \& Perreira, K. M. (2021). The Covid19 pandemic and mental health of first-year college students: Examining the effect of Covid-19 stressors using longitudinal data. PloS One, 16(3), e0247999. https://doi.org/10.1371/journ al.pone.0247999

Galea, S., Merchant, R. M., \& Lurie, N. (2020). The mental health consequences of Covid-19 and physical distancing: The need for prevention and early intervention. JAMA Internal Medicine, 180(6), 817-818. https://doi.org/10.1001/jamainternmed.2020.1562

Glavin, P., \& Schieman, S. (2014). Control in the face of uncertainty: Is job insecurity a challenge to mental health benefits of control beliefs? Social Psychology Quarterly, 77(4), 319-343. https://doi. org/10.1177/0190272514546698

Hayes, A. F. (2020). PROCESS (Version 3.5.3) [Computer software]. Retrieved from http://www.processmacro.org/download.html (last access July 06, 2021).

Henrich, J., Heine, S. J., \& Norenzayan, A. (2010). The weirdest people in the world? The Behavioral and Brain Sciences, 33(2-3), 61-83. https://doi.org/10.1017/S0140525X0999152X

Islam, M. S., Sujan, M. S. H., Tasnim, R., Ferdous, M. Z., Masud, J. H. B., Kundu, S., Mosaddek, A. S. M., Choudhuri, M. S. K., Kircaburun, K., \& Griffiths, M. D. (2020). Problematic internet use among young and adult population in Bangladesh: Correlates with lifestyle and online activities during the Covid-19 pandemic. Addictive Behaviors Reports, 12, 100311. https://doi.org/ 10.1016/j.abrep.2020.100311

Jacob, L., Tully, M. A., Barnett, Y., Lopez-Sanchez, G. F., Butler, L., Schuch, F., López-Bueno, R., McDermott, D., Firth, J., Grabovac, I., Yakkundi, A., Armstrong, N., Young, T., \& Smith, L. (2020). The relationship between physical activity and mental health in a sample of the UK public: A cross-sectional study during the implementation of Covid-19 social distancing measures. Mental Health and Physical Activity, 19, 100345. https://doi.org/10. 1016/j.mhpa.2020.100345

Johnston, S. A., Roskowski, C., He, Z., Kong, L., \& Chen, W. (2020). Effects of team sports on anxiety, depression, perceived stress, and sleep quality in college students. Journal of American College Health. https://doi.org/10.1080/07448481.2019.1707836

Kathirvel, N. (2020). Post Covid-19 pandemic mental health challenges. Asian Journal of Psychiatry, 53, 102430. https://doi.org/ 10.1016/j.ajp.2020.102430

Keyes, C. L. M. (2005). Mental illness and/or mental health? Investigating axioms of the complete state model of health. Journal of Consulting and Clinical Psychology, 73(3), 539-548. https://doi. org/10.1037/0022-006X.73.3.539

Kiecolt, K. J., Hughes, M., \& Keith, V. M. (2009). Can a high sense of control and John Henryism be bad for mental health? The Sociological Quarterly, 50(4), 693-714. https://doi.org/10.1111/j.15338525.2009.01152.x

Lemenager, T., Neissner, M., Koopmann, A., Reinhard, I., Georgiadou, E., Müller, A., Kiefer, F., \& Hillemacher, T. (2020). Covid-19 lockdown restrictions and online media consumption in Germany. International Journal of Environmental Research and Public Health, 18(1), 14. https://doi.org/10.3390/ijerph18010014

Lesser, I. A., \& Nienhuis, C. P. (2020). The impact of Covid-19 on physical activity behavior and well-being of Canadians. International Journal of Environmental Research and Public Health, 17(11), 3899. https://doi.org/10.3390/ijerph17113899

Li, Y., Zhao, J., Ma, Z., McReynolds, L. S., Lin, D [Dihuan], Chen, Z., Wang, T., Wang, D., Zhang, Y., Zhang, J., Fan, F., \& Liu, X. (2021). Mental health among college students during the Covid19 pandemic in China: A 2-wave longitudinal survey. Journal of Affective Disorders, 281, 597-604. https://doi.org/10.1016/j.jad. 2020.11.109.
Liu, C. H., Zhang, E., Wong, G. T. F., Hyun, S., \& Hahm, H. C. (2020). Factors associated with depression, anxiety, and PTSD symptomatology during the Covid-19 pandemic: Clinical implications for U.S. young adult mental health. Psychiatry Research, 290 , 113172. https://doi.org/10.1016/j.psychres.2020.113172

Lovibond, P. F., \& Lovibond, S. H. (1995). The structure of negative emotional states: Comparison of the depression anxiety stress scales (DASS) with the Beck depression and anxiety inventories. Behaviour Research and Therapy, 33(3), 335-343. https://doi.org/ 10.1016/0005-7967(94)00075-U

Lukat, J., Margraf, J., Lutz, R., van der Veld, W. M., \& Becker, E. S. (2016). Psychometric properties of the positive mental health scale (PMH-scale). BMC Psychology, 4, 8. https://doi.org/10. 1186/s40359-016-0111-X

Maercker, A., Chi Zhang, X., Gao, Z., Kochetkov, Y., Lu, S., Sang, Z., Yang, S., Schneider, S., \& Margraf, J. (2015). Personal value orientations as mediated predictors of mental health: A threeculture study of Chinese, Russian, and German university students. International Journal of Clinical and Health Psychology, 15(1), 8-17. https://doi.org/10.1016/j.ijchp.2014.06.001

Maier, S. F., \& Seligman, M. E. P. (2016). Learned helplessness at fifty: Insights from neuroscience. Psychological Review, 123(4), 349-367. https://doi.org/10.1037/rev0000033

Maugeri, G., Castrogiovanni, P., Battaglia, G., Pippi, R., D’Agata, V., Palma, A., Di Rosa, M., \& Musumeci, G. (2020). The impact of physical activity on psychological health during Covid-19 pandemic in Italy. Heliyon, 6(6), e04315. https://doi.org/10.1016/j. heliyon.2020.e04315

Mikkelsen, K., Stojanovska, L., Polenakovic, M., Bosevski, M., \& Apostolopoulos, V. (2017). Exercise and mental health. Maturitas, 106, 48-56. https://doi.org/10.1016/j.maturitas.2017.09.003

Milton, K., Bull, F. C., \& Bauman, A. (2011). Reliability and validity testing of a single-item physical activity measure. British Journal of Sports Medicine, 45(3), 203-208. https://doi.org/10. 1136/bjsm.2009.068395

Ozdemir, F., Cansel, N., Kizilay, F., Guldogan, E., Ucuz, I., Sinanoglu, B., Colak, C., \& Cumurcu, H. B. (2020). The role of physical activity on mental health and quality of life during Covid-19 outbreak: A cross-sectional study. European Journal of Integrative Medicine, 40, 101248. https://doi.org/10.1016/j. eujim.2020.101248

Paredes, M. R., Apaolaza, V., Fernandez-Robin, C., Hartmann, P., \& Yañez-Martinez, D. (2021). The impact of the Covid-19 pandemic on subjective mental well-being: The interplay of perceived threat, future anxiety and resilience. Personality and Individual Differences, 170, 110455. https://doi.org/10.1016/j. paid.2020.110455

Pearlin, L. I., \& Schooler, C. (1978). The structure of coping. Journal of Health and Social Behavior, 19(1), 2-21. https://doi.org/ $10.2307 / 2136319$

Pierce, M., Hope, H., Ford, T., Hatch, S., Hotopf, M., John, A., Kontopantelis, E., Webb, R., Wessely, S., McManus, S., \& Abel, K. M. (2020). Mental health before and during the Covid-19 pandemic: A longitudinal probability sample survey of the UK population. The Lancet Psychiatry, 7(10), 883-892. https://doi. org/10.1016/S2215-0366(20)30308-4

Rebar, A. L., Stanton, R., Geard, D., Short, C., Duncan, M. J., \& Vandelanotte, C. (2015). A meta-meta-analysis of the effect of physical activity on depression and anxiety in non-clinical adult populations. Health Psychology Review, 9(3), 366-378. https:// doi.org/10.1080/17437199.2015.1022901

Rodríguez-Hidalgo, A. J., Pantaleón, Y., Dios, I., \& Falla, D. (2020). Fear of Covid-19, stress, and anxiety in university undergraduate students: A predictive model for depression. Frontiers in Psychology, 11, 591797. https://doi.org/10.3389/fpsyg.2020. 591797 
Ross, C. E., \& Mirowsky, J. (2013). The sense of personal control: Social structural causes and emotional consequences. In C. S. Aneshensel, J. C. Phelan, \& A. Bierman (Eds.), Handbook of the sociology of mental health. $2^{\text {nd }}$ ed. (pp. 379-402). Springer. https://doi.org/10.1007/978-94-007-4276-5_19

Salari, N., Hosseinian-Far, A., Jalali, R., Vaisi-Raygani, A., Rasoulpoor, S [Shna], Mohammadi, M., Rasoulpoor, S [Shabnam], \& Khaledi-Paveh, B. (2020). Prevalence of stress, anxiety, depression among the general population during the Covid-19 pandemic: A systematic review and meta-analysis. Globalization and Health, 16(1), 57. https://doi.org/10.1186/s12992-020-00589-w

Sallis, J. F., \& Pratt, M. (2020). Multiple benefits of physical activity during the coronavirus pandemic. Revista Brasileira De Atividade Física \& Saúde, 25, e0112. https://doi.org/10.12820/rbafs. $25 \mathrm{e} 0112$

Schönfeld, P., Brailovskaia, J., \& Margraf, J. (2017). Positive and negative mental health across the lifespan: A cross-cultural comparison. International Journal of Clinical and Health Psychology, 17(3), 197-206. https://doi.org/10.1016/j.ijchp.2017.06.003

Simpson, R. J., \& Katsanis, E. (2020). The immunological case for staying active during the Covid-19 pandemic. Brain, Behavior, and Immunity, 87, 6-7. https://doi.org/10.1016/j.bbi.2020.04.041

Southwick, F. S., \& Southwick, S. M. (2018). The loss of a sense of control as a major contributor to physician burnout: A neuropsychiatric pathway to prevention and recovery. JAMA Psychiatry, 75(7), 665-666. https://doi.org/10.1001/jamapsychiatry.2018. 0566

Šrol, J., Ballová Mikušková, E., \& Čavojová, V. (2021). When we are worried, what are we thinking? Anxiety, lack of control, and conspiracy beliefs amidst the Covid-19 pandemic. Applied Cognitive Psychology, 35(3), 720-729. https://doi.org/10.1002/acp.3798

Steptoe, A., \& Poole, L. (2016). Control and stress. In G. Fink (Ed.), Stress: Concepts, cognition, emotion, and behavior: Handbook of stress series, volume 1 (pp. 73-80). Elsevier. https://doi.org/10. 1016/B978-0-12-800951-2.00008-X

Tsamakis, K., Tsiptsios, D., Ouranidis, A., Mueller, C., Schizas, D., Terniotis, C., Nikolakakis, N., Tyros, G., Kympouropoulos, S., Lazaris, A., Spandidos, D. A., Smyrnis, N., \& Rizos, E. (2021). Covid-19 and its consequences on mental health (review). Experimental and Therapeutic Medicine, 21(3), 244. https://doi.org/10. 3892/etm.2021.9675

Tso, R. V., \& Cowling, B. J. (2020). Importance of face masks for Covid-19: A call for effective public education. Clinical Infectious Diseases, 71(16), 2195-2198. https://doi.org/10.1093/cid/ciaa593

Woods, J. A., Hutchinson, N. T., Powers, S. K., Roberts, W. O., GomezCabrera, M. C., Radak, Z., Berkes, I., Boros, A., Boldogh, I., Leeuwenburgh, C., Coelho-Júnior, H. J., Marzetti, E., Cheng, Y., Liu, J., Durstine, J. L., Sun, J [Junzhi], \& Ji, L. L. (2020). The Covid-19 pandemic and physical activity. Sports Medicine and Health Science, 2(2), 55-64. https://doi.org/10.1016/j.smhs.2020. 05.006
World Health Organization (2010). Global recommendations on physical activity for health. Retrieved from https://apps.who.int/iris/ bitstream/handle/10665/44399/9789241599979_eng.pdf?seque nce $=1$ (last access July 06, 2021).

World Health Organization (2020a). Coronavirus disease 2019 (Covid19): Situation report. Retrieved from https://www.who.int/docs/ default-source/coronaviruse/situation-reports/20200311-sitrep-51covid-19.pdf?sfvrsn=1ba62e57_10 (last access July 06, 2021).

World Health Organization (2020b). Covid-19 strategy update, 14 April 2020. Retrieved from https://www.who.int/publications/i/ item/covid-19-strategy-update---14-april-2020 (last access July 06, 2021).

World Health Organization (2020c). Mental health and psychosocial considerations during the Covid-19 outbreak, 18 March 2020. Retrieved from https://apps.who.int/iris/bitstream/handle/10665/ 331490/WHO-2019-nCoV-MentalHealth-2020.1-eng.pdf (last access July 06, 2021).

World Health Organization (2021a). Status of Covid-19 vaccines within WHO EUL/PQ evaluation process: Guidance document, 16 June 2021. Retrieved from https://extranet.who.int/pqweb/sites/default/ files/documents/Status_of_COVID-19_Vaccines_within_WHO EUL-PQ_evaluation_process-16June2021_Final.pdf. Access 6 Jul 2021.

World Health Organization (2021b). Weekly epidemiological update on Covid-19, 8 June 2021. Retrieved from https://www.who.int/publi cations/m/item/weekly-epidemiological-update-on-covid-19---8june-2021 (last access July 06, 2021).

Xiang, M.-Q., Tan, X.-M., Sun, J [Jian], Yang, H.-Y., Zhao, X.-P., Liu, L., Hou, X.-H., \& Hu, M. (2020). Relationship of physical activity with anxiety and depression symptoms in Chinese college students during the Covid-19 outbreak. Frontiers in Psychology, 11, 582436. https://doi.org/10.3389/fpsyg.2020.582436

Yang, H., \& Ma, J. (2020). How an epidemic outbreak impacts happiness: Factors that worsen (vs. protect) emotional well-being during the coronavirus pandemic. Psychiatry Research, 289, 113045. https://doi.org/10.1016/j.psychres.2020.113045

Ye, Z., Yang, X., Zeng, C., Wang, Y., Shen, Z., Li, X., \& Lin, D [Danhua] (2020). Resilience, social support, and coping as mediators between Covid-19-related stressful experiences and acute stress disorder among college students in China. Applied Psychology: Health and Well-Being, 12(4), 1074-1094. https://doi.org/10. 1111/aphw.12211

Publisher's Note Springer Nature remains neutral with regard to jurisdictional claims in published maps and institutional affiliations. 